\title{
A INFLUÊNCIA DA INICIATIVA HOSPITAL AMIGO DA CRIANÇA NA AMAMENTAÇÃO
}

Valéria Lerch Lunardi* Michele Salum Bulhosa**

\section{Resumo}

O trabalho investiga a percepção de mulheres que foram parturientes num Hospital Amigo da Criança (HAC) sobre a influência dessa proposta na sua decisão de aleitar. Realizamos entrevistas semi-estruturadas enfocando o processo de aleitamento materno (AM), expectativas, vivências e importância da equipe de saúde. A análise de conteúdo dos dados realizou-se a partir dos "Dez Passos para o Sucesso do Aleitamento Materno". Constatamos que em situações reconhecidas pelas mulheres como problemáticas e não encontrando respostas que atenuassem diferentes desconfortos e o sofrimento vivenciados, frente ao seu desejo de amamentar, interromperam o AM. Consideramos que com a manutenção do apoio à mulher, pelo HAC, para o enfrentamento dessas dificuldades, sua influência pode ser decisiva para a continuidade do AM.

Descritores: amamentação; autonomia; Hospital Amigo da Criança

\begin{abstract}
The paper investigates the awareness of women who gave birth in a 'Friend of Children' Hospital (FCH) of the influence of this campaign on their decision to breast-feed. We conducted semi-structured interviews, focusing the maternal breast-feeding process, expectations, experiences, and the importance of the health staff. The data analysis was based on the "Ten Steps to Successful Maternal Breast-Feeding." We found out that in situations regarded by women as problematic and lacking in answers that could attenuate their discomfort and suffering in the face of their desire to breast-feed, they stopped breast-feeding. We believe that by maintaining the $F C H$ support to women (so that they can face those difficulties), its influence can be decisive to the continuation of breast-feeding. Descriptors: breast-feeding; autonomy; 'Friend of Children' Hospital

Title: The influence of the 'Friend of Children Hospital' campaign on breast-feeding
\end{abstract}

\begin{abstract}
Resumen
El trabajo investiga la percepción de las mujeres que eran parturientas en un Hospital Amigo del Niño (HAN) sobre la influencia de esta propuesta en su decisión de amamantar. Realizamos entrevistas semiestructuradas enfocando el proceso de amamantar (AM); las expectativas; las vivencias; la importancia del equipo de salud, entre otros. El análisis de contenido de los datos se realizó a partir de los «Diez Pasos para el Éxito de Amamantamiento Materno». Constatamos que en situaciones reconocidas por las mujeres como problemáticas y no encontrando respuestas que atenuaran diferentes incomodidades y el sufrimiento vivenciado, frente a su deseo de amamantar, interrumpieron el AM. Consideramos que con el mantenimiento del apoyo a la mujer, por el HAC para el enfrentamiento de esas dificultades, su influencia puede ser decisiva para la
\end{abstract} continuidad del AM.

Descriptores: amamantamiento materno; autonomía personal; Hospital Amigo del Niño Título: La influencia de la Iniciativa Hospital Amigo del Niño en el amamantamiento

\section{Introdução}

A proposta da Iniciativa do Hospital Amigo da Criança (IHAC) tem sua origem, em 1990, através do Fundo das Nações Unidas pela Infância (UNICEF) e da Organização Mundial da Saúde (OMS), com o objetivo de promover o aleitamento materno $(\mathrm{AM})^{(1)}$. É sabido, no entanto, que vários elementos como a cultura, a história familiar e pessoal, a insegurança e a desinformação podem interferir e comprometer esta prática(2). Assim, tendo em vista o recebimento do título de HAC por uma instituição do extremo sul do país em abril de 2002, optamos por conhecer se a prática de seus profissionais de saúde, na percepção de mulheres, favoreceu sua decisão de aleitar seus filhos nascidos nesta instituição.

\section{Iniciativa do Hospital Amigo da Criança -IHAC}

O objetivo básico da IHAC consiste na mobilização de profissionais de saúde e funcionários de hospitais e maternidades para mudanças em rotinas e condutas, visando prevenir o desmame precoce. Os motivos que levaram a OMS e o UNICEF a fazer opção por atuar junto aos hospitais se devem aos fatores envolvidos no desestímulo à amamentação, relacionados com informações insuficientes e práticas inadequadas atribuídas à unidade de saúde e ao profissional de saúde. O conjunto de medidas para atingir as metas contidas na Declaração de Innocenti, foi denominado de "Dez Passos para o Sucesso do Aleitamento Materno", elaborado por um grupo de especialistas de saúde e nutrição de vários países. Para receber o título de Hospital Amigo da Criança (HAC), as instituições são submetidas a avaliações, tendo com critério o cumprimento global de $80 \%$ de cada um dos dez passos para o sucesso do $\mathrm{AM}^{(3)}$.

Os hospitais credenciados como Amigo da Criança, uma vez qualificados, passam a atuar como local de treinamento de equipes multiprofissionais da área da saúde, passando a ser reconhecidos como centros de "referência em aleitamento materno" em nível local ou regional. Esses hospitais, também, caracterizam-se por garantir a continuidade da lactação de forma exclusiva nos primeiros seis meses dentro e fora da instituição, ou seja, diferenciam-se por ofertar condições para que a puérpera tenha o direito a amamentar, a acompanhamento adequado, à orientação e informações necessárias para o sucesso do $\mathrm{AM}^{(1)}$.

\section{Aleitamento Materno}

As vantagens do AM para o bebê são inúmeras ${ }^{(2,4)}$. O processo vivenciado pela mulher, no entanto, envolve não somente sua vontade e decisão de amamentar, mas também a revisão de seus papéis sociais e o equilíbrio familiar. A cultura familiar se faz presente na prática do AM, influenciando a mulher com seus conhecimentos. Na decisão da mulher de aleitar seu filho, além de sua história e cultura familiar, destaca-se ainda a importância de um familiar, significante no processo, ser preparado pelo profissional/ instituição de saúde para participar do $\mathrm{AM}^{(5)}$. É preciso, então, que a mulher seja vista como um todo, um ser integral e singular. Dessa forma, valorizar suas experiências assim como sua realidade e expectativas frente ao ser mulhermãe podem influenciar no sucesso da prática do $\mathrm{AM}^{(6)}$.

\section{Metodologia}

Inicialmente selecionamos mulheres que foram parturientes em um HAC, entre maio e dezembro de 2002, a partir de dados obtidos junto ao Serviço de Arquivo Médico e Estatístico (SAME) de uma instituição do extremo sul do país. Contactamos estes sujeitos, solicitamos sua autorização prévia, agendando local e horário para a entrevista. Solicitarmos seu

\footnotetext{
* Enfermeira. Doutora em Enfermagem. Departamento de Enfermagem da Fundação Universidade Federal do Rio Grande (FURG). Membro do Núcleo de Pesquisas em Enfermagem e Saúde. ${ }^{\star \star}$ Acadêmica do curso de Enfermagem e Obstetrícia da FURG- Bolsista PIBIC/ CNPq.

E-mail do autor: vlunardi@terra.com.br
} 
consentimento livre e esclarecido ${ }^{(7)}$ e realizamos entrevistas semiestruturadas $^{(8)}$ com quatorze mulheres, enfocando: o processo de AM; expectativas; vivências; importância e influências da equipe de saúde, durante o alojamento conjunto e no puerpério tardio, no processo de decisão em aleitar. Após a transcrição das fitas, elaboramos um quadro-síntese de alguns achados, procedendo, depois, ao aprofundamento da análise de conteúdo dos dados, a partir do "Dez Passos para o Sucesso do AM".

\section{Análise e interpretação dos dados}

Informar todas as gestantes atendidas sobre as vantagens e o manejo da amamentação constitui-se no passo 3 e expressa o compromisso da equipe com o proposto na IHAC. O AM é determinado em parte por concepções já formadas durante a gestação, a partir de crenças, conhecimentos, sentimentos e experiências precedentes a esta prática ${ }^{(9)}$. Dessa forma, a discussão no pré-natal necessita abranger a importância do AM exclusivo nos primeiros meses de vida, as vantagens do $A M$ e o manejo básico da amamentação(10). Consideramos que o pré-natal necessita ir além, ou seja, rever o significado do AM para a mulher, como a mesma poderá manter a lactação, a anticoncepção e os desafios e possíveis dificuldades de aleitar, favorecendo a instrumentalização da mulher para o seu próprio cuidado com maior autonomia e conhecimento, para o cuidado de si, no exercício desta prática.

Das mulheres entrevistadas, apenas uma fez seu prénatal nesta instituição, reconhecendo-se instrumentalizada para o AM, no que se refere ao preparo da mama. A grande maioria fez pré-natal em clínicas particulares, cujas orientações recebidas enfocaram predominantemente o preparo da mama, porém as mulheres não reconheceram ter sido orientadas para o manejo do AM. Tal percepção aponta para a importância que este HAC mobilize não apenas seus profissionais de saúde, mas também construa estratégias para estimular a participação de outras equipes multiprofissionais da rede privada e pública, assumindose como referência regional em AM, comprometendo-se com a mudança de indicadores em relação a esta prática, já que se constitui num dos poucos HAC do extremo sul do país.

No que se refere à necessidade de ajudar as mães a iniciar a amamentação na primeira meia hora após o parto (passo 4), a maioria das mulheres reconheceu que, ainda na sala de recuperação anestésica (SRA), o bebê foi colocado em seu seio para amamentar. Entretanto, algumas não se reconheceram ajudadas pelo desconforto sentido frente a sua incapacidade, pela anestesia, de mover-se, segurar seus bebês e cuidá-los de modo apropriado. Já as mulheres que tiveram a companhia de uma pessoa significativa, familiar ou amiga, referiram segurança e conforto e sentiram-se estimuladas ao AM. Esse passo parece muito importante para o sucesso do $\mathrm{AM}$, pois se a primeira mamada ocorrer tardiamente pode ser mais difícil estabelecer um adequado fluxo de leite(2).

Assim, parece relevante o entendimento de que estimular o AM não signifique apenas que a criança seja levada ao peito da mulher, mas requer ajudá-la a iniciar a amamentação, isto é, que a equipe de saúde se mobilize para assegurar e transmitir-lhe presença, segurança, apoio, de modo a que este encontro inicial mãe-filho, provocado pela necessidade e desejo de amamentar, possa ser positivo. No que se refere aos recursos humanos necessários para garantir esta relação de ajuda proposta, parece importante destacar que um HAC recebe um estímulo financeiro de $40 \%$ no prénatal e $10 \%$ nos procedimentos obstétricos ${ }^{(1-2)}$, justamente por ter recebido este título, o que necessita ser reconhecido como investimento a ser aplicado para garantir o alcance do que é preconizado nesta iniciativa.

Associado a este passo 4, encontra-se o 5 - Mostrar às mães como amamentar e como manter a lactação, mesmo se vierem a ser separadas de seus filhos. É importante que as puérperas sejam orientadas pelos profissionais como fazer a drenagem manual do leite, posicionar corretamente o bebê e avaliar sua pega ${ }^{(10)}$. Constatamos que (M3) foi orientada sobre amamentação em livre demanda pelo pediatra; (M7 e M8) pelos funcionários do banco de leite enfocando a pega, a extração do leite com a seringa e a prevenção de fissura com uso do mamão e do leite materno; e outras (M1, M4, M5, M9, M10, M11), ainda, pela equipe de enfermagem, abordando aspectos gerais como pega, proibição do uso de chupetas, prevenção de fissura com o uso do mamão e do leite materno. Porém, a maioria, mesmo não fazendo referência ao recebimento de orientações sobre o AM, expressou a restrição do uso de bicos e mamadeiras. Algumas (M2, M6, M12, M13, M14) não fizeram referência a qualquer orientação sobre o AM.

As mulheres que referiram precisar realizar a expressão do leite, utilizaram máquinas adquiridas em farmácias, desconhecendo o método de extração manual do leite. Consideramos que esse passo, quando bem trabalhado pela equipe de saúde com as mulheres, necessita ultrapassar o puerpério imediato e buscar prevenir o desmame, favorecendo a instrumentalização da puérpera para o enfrentamento de possíveis dificuldades como ingurgitamento mamário, fissuras, hipergalactorréia, dor, desconfortos, o que pode estar associado ao seu retorno às atividades de estudo e /ou trabalho.

Tais problemas freqüentemente não ocorrem durante o período de tempo bastante reduzido da internação hospitalar. Geralmente, em cesáreas, este não ultrapassa 24 horas, apesar do determinado pelo Ministério da Saúde, que preconiza no mínimo 48 horas de internação para o parto cesárea e 24 horas para parto normal(11). O tempo parece reduzido e/ou subutilizado para permitir um melhor acompanhamento da adaptação mãefilho, da iniciação dos cuidados para com o recém-nascido, identificação de dificuldades e esclarecimento de dúvidas. Novamente, consideramos que o compromisso da equipe com a IHAC requer sua permanente mobilização e envolvimento com a efetividade do $\mathrm{AM}^{(12)}$, o que significa um olhar atento para este processo, uma relação de disponibilidade para interagir com o binômio mãe-filho, perceber facilidades e dificuldades, trocar informações, demonstrar interesse e desejo de ajudar. A ocorrência de possíveis dificuldades enfrentadas pela mulher poderia ser reduzida ou prevenida, buscando confortá-la e orientá-la sobre o manejo com seu filho durante a apojadura do leite, além de garantir o respaldo do hospital para o esclarecimento de qualquer dúvida ou intercorrência.

Entendemos que o passo 8 - Encorajar a amamentação sob livre demanda interliga-se com o passo 5, pois está fortemente articulado à manutenção da lactação, dado que quanto mais o bebê suga, mais estimula a produção de leite.

Conforme exigências da IHAC, é preciso Praticar o alojamento conjunto (AC)- permitir que mães e bebês permaneçam juntos 24 horas por dia (passo 7), num mesmo ambiente, até a alta hospitalar. Este sistema possibilita a prestação dos cuidados assistenciais, bem como a orientação à mãe sobre cuidados com a saúde do binômio mãe-filho(12). É importante, ainda, ressaltar o caráter educativo do sistema de AC, não apenas informativo, pois neste processo se faz necessário respeitar as representações sociais dos pais, estimulando sua autonomia através do auto-cuidado. As orientações fornecidas necessitam agregar-se ao conhecimento prévio dos pais, de forma a reforçar condutas positivas de auto-cuidado ${ }^{(13-14)}$.

A equipe de saúde tem como função facilitar esse processo de aprendizagem e para isso é primordial a sua organização e coesão na definição de seus papéis, na conjugação de esforços para práticas convergentes durante a assistência ao binômio mãe-filho ${ }^{(15)}$. A colocação do binômio no centro da atenção da assistência exige uma ação integrada dos profissionais da equipe de saúde ${ }^{(16)}$.

O choro, por vezes contínuo, do bebê, deixa as mulheres inseguras, dado que as mesmas associam diretamente o choro 
à fome do bebê e à qualidade do leite materno ${ }^{(9,17)}$. Entretanto, esta manifestação pode decorrer do frio, calor, fraldas molhadas, de inúmeros desconfortos, dado que o choro é uma das únicas formas de comunicação do recém-nascido(4). Assim, destacamos que os dez passos foram idealizados para facilitar o AM e necessitam de certa flexibilidade levando em consideração a singularidade de cada binômio. M6 referiu ter enfrentado o choro intermitente de seu filho e desamparo para o enfrentamento desta situação, além de cansaço, medo e sentimento de incapacidade. A equipe de saúde necessita estar atenta para a singularidade da mãe, para seu estado físico e emocional, assegurando-lhe descanso, de tal forma que possa iniciar o AM eficazmente, mesmo que isso signifique afastar o bebê por algumas horas da puérpera.

Constatamos divergências de orientação entre os pediatras quanto ao passo 6 - Não dar a recém-nascido nenhum outro alimento ou bebida além do leite materno, a não ser que tenha indicação clínica, já que (M6 e M7) referiram ter recebido prescrição de leite artificial pelos médicos de convênios privados que as atendiam, frente a sua dificuldade de amamentar devido, respectivamente, ao choro contínuo do bebê e ao retorno aos estudos, o que Ihes provocou um impasse, em especial, pelas opiniões e manifestações de familiares quanto à conduta correta em relação à alimentação do seu filho. Como já referido, ressaltamos a responsabilidade do HAC em assumir seu papel como centro de referência, tendo em vista a promoção do AM, destacando a necessidade de promover encontros com profissionais da saúde da comunidade em geral, de modo a discutir e aprofundar questões referentes a esta prática, a seu estímulo, instrumentalização, apoio, dificuldades e estratégias. É possível perceber que, após fazer uma reflexão das necessidades da mãe e de seu filho, o que for interpretado como prioritário e mais eficaz será implementado(9), ou seja, diante do enfrentamento de dificuldades no AM, da falta de apoio familiar e profissional para sua prática, de manifestações de desconforto do bebê, do sentimento de incapacidade da mãe, dentre outras, a prescrição de leite artificial pode constituir-se na melhor e mais rápida solução: (...) pra não dá muito trabalho (M7).

Diante do passo 9 - Não dar bicos artificiais ou chupetas a crianças amamentadas, as próprias mulheres justificam o seu uso como um recurso que acalenta e acalma a criança, demonstrando, em sua maioria, desconhecimento das justificativas para a sua proibição. Tendo em vista que o HAC apresenta um potencial para ser um multiplicador de informações corretas sobre o AM, buscando promovê-lo e apoiá-lo( ${ }^{(1)}$, faz-se necessário que os profissionais, antes de usarem termos e atitudes de coação e proibição em relação ao uso de chupetas, discutam esta questão com as mães e com seus acompanhantes, suas vantagens e desvantagens, favorecendo suas opções no cuidado das crianças, com compreensão dos seus riscos e benefícios, destacando que o uso da chupeta pode ser um fator predisponente para o desmame precoce ${ }^{(18)}$.

Neste sentido, constatamos que mulheres com expectativas e antecedentes culturais positivos para o AM, associadas à referência de ausência de qualquer dificuldade no aleitamento, apresentaram sucesso em amamentar os filhos, mesmo optando por "desobedecer" as proibições impostas pelos profissionais do HAC, permitindo o uso de chupeta pela criança. Percebemos o pleno exercício de autonomia das mulheres, que se fundamenta na defesa da liberdade, estando associada à "privacidade, livre escolha, escolha de posição moral própria e aceitação de responsabilidade pela escolha própria" (19: 22) :

[...] na hora eu mesmo penso e faça aquilo que eu quero, porque eu sou a mãe. Claro que prejuízos, a gente sabe que tem, como tudo na vida. Cheguei em casa: melzinho e funchicória (M-5).
O depoimento de (M5) demonstra que antes de condutas que apontem para a necessidade de adesão e sujeição das clientes ao determinado pelos profissionais de saúde, faz-se necessário trocar conhecimentos, crenças, vivências, já que a mulher não negará seus saberes construídos histórica e culturalmente porque assim o desejam os profissionais de saúde, e nem seus saberes e verdades profissionais constituem-se nas únicas verdades e saberes. Apenas o encontro e o diálogo de diferentes saberes e verdades garantirá às clientes seu reconhecimento como sujeito e não como coisa a ser subjugada. A beneficência prevê que os profissionais de saúde ajam no interesse dos pacientes ${ }^{(20)}$, o que requer não sua obediência ao que acreditamos e reconhecemos como verdade, mas sua instrumentalização com os saberes que dispomos para sua tomada de decisão.

Parece importante, ainda, destacar que (M9) foi orientada pelo próprio médico ao uso do bico. No entanto, ela como outras (M11, M13 e M14), tentaram utilizar este recurso para acalmar o bebê, o que não foi aceito pela criança. Pode-se, então, inferir que o uso do bico pelo bebê parece mais resultante da aceitação pela própria criança do que de decisão materna.

Associada à preocupação com o manejo da amamentação e sua manutenção, o passo 10 do AM recomenda Encorajar o estabelecimento de grupos de apoio à amamentação, para onde as mães devem ser encaminhadas por ocasião da alta hospitalar. O ambulatório de lactação/ seguimento é de extrema importância, principalmente nos primeiros meses de vida do lactente ${ }^{(10)}$. Nenhuma das mulheres foi encaminhada a grupos de apoio que teriam como função fortalecer e disseminar o hábito de amamentar.

Este hospital, no entanto, dispõe de um serviço do disque amamentação, sobre o qual diferentes percepções foram manifestadas. Mulheres como (M3) que apresentou fissuras e ingurgitamento como dificuldade, ao primeiro contato com este serviço, conseguiu contornar este problema e aleitar com sucesso. Já (M2), enfrentando, como dificuldade, demora na apojadura e hipogalactorréia buscou várias vezes o serviço do disque amamentação, insistentemente, no intuito de não usar mamadeiras e bicos, até receber como resposta que não há mais o que fazer. É necessário destacar, novamente, que os hospitais credenciados caracterizam-se por garantir às mulheres, tanto no hospital como fora, a continuidade do aleitamento materno exclusivo nos primeiros seis meses, requerendo o oferecimento de condições que assegurem seu direito de amamentar, acompanhamento, orientação e informações necessárias para o sucesso da amamentação por um tempo prolongado $^{(1)}$, o que expressaria o compromisso da instituição com o proposto na IHAC.

Finalizando esta análise, resgatamos os passos 1 - Ter uma norma escrita sobre aleitamento materno, a qual deve ser rotineiramente transmitida a toda a equipe do serviço e o 2 Treinar toda a equipe, capacitando-a para implementar esta norma, já que entendemos a necessidade de não apenas estabelecer normas escritas, mas garantir a educação em serviço de modo a que sua implementação seja alcançada e percebida pela comunidade atendida. Esta normatização tem o objetivo de proteger a amamentação, necessitando abranger todos os passos propostos e ser de fácil acesso e compreensão para pacientes e funcionários. Apesar da percepção das mulheres da presença de normas escritas, as quais se restringem aos "Dez passos para o Sucesso do AM", afixadas em quadros nas paredes do hospital, e não a uma norma específica desta instituição, parece-nos que alguns dos problemas vivenciados pelas mulheres quanto ao AM, durante a internação hospitalar e após a sua alta, e a falta de ressonância por parte de profissionais na sua abordagem e atendimento, demonstram a necessidade de maior ênfase na capacitação dos profissionais para sua implementação bem como no seu compromisso e envolvimento com esta proposta. 
A IHAC requer, ainda, que todos os funcionários recebam um treinamento de no mínimo 18 horas, com abrangência prática de pelo menos oito dos Dez Passos ${ }^{(10)}$; sendo que funcionários novos devem receber orientação quando iniciarem o seu trabalho. Assim, já foram realizados 11 cursos de capacitação com os funcionários desta instituição. Destacamos, entretanto, que tão importante quanto a adesão e presença dos profissionais a estes cursos, se faz necessária sua sensibilização para a importância do aleitamento materno, para a qualidade dos cuidados prestados às mães e aos recém-natos que demonstrem seu permanente e contínuo comprometimento com a promoção e manutenção do $\mathrm{AM}$, o que abrange tanto a prevenção como o enfrentamento de conflitos e dificuldades vivenciadas pela mulher antes e durante a prática do AM.

\section{Considerações finais}

A prática do AM é uma experiência que envolve fatores relacionados à criança e à mulher e parece não depender exclusivamente da sua decisão de amamentar durante a gestação ${ }^{(9)}$. A tomada de decisão em amamentar depende do que considera como prioritário para ela e seu filho; logo, a mulher nesse processo está continuamente avaliando os riscos e benefícios de alimentar seu filho com o próprio leite.

O aleitamento não é uma prática fácil, exigindo uma adaptação da mulher ao seu novo papel de mulher-mãe. Logo, fatores como falta de apoio, experiências negativas do AM, retorno ao trabalho, problemas mamários, depressão pós-parto, auto-imagem prejudicada, condição biológica da mulher, papel da mulher na família podem dificultar o $\mathrm{AM}^{(20-23)}$. Percebemos que as mulheres entrevistadas utilizaram vários meios para vencer tais dificuldades como: busca do auxílio do médico, do HAC e dos saberes populares. Nem sempre, entretanto, alcançaram o sucesso desejado.

Assim, mulheres que apresentaram dificuldades mais facilmente enfrentadas, independentemente de apoio ou de história familiar de AM e de buscarem ajuda do HAC, de seus médicos ou da cultura popular, conseguiram solucioná-los e amamentar seus filhos, mesmo tendo utilizado chupetas e até leites artificiais inicialmente.

Ressaltamos, ainda, que o manejo do AM não inclui apenas orientar sobre a pega correta, mas, também, sobre como realizar a drenagem manual do leite e armazená-lo. Nenhuma das mulheres refere ter sido orientada a esse respeito, apesar de desempenharem atividades fora do lar (estudo ou trabalho). Instrumentalizar-se para manter a lactação, mesmo quando separada de seu filho (passo 5), constitui-se em um direito a ser garantido à mulher. Além disso, a drenagem manual do leite não causa dor e pode ser muito útil nos primeiros quinze dias pós-parto pelo fluxo desregulado de leite ${ }^{(4)}$, prevenindo ingurgitamento, fissuras, dor no momento da lactação, dificuldade na pega, constrangimento pelo extravasamento do leite e desconforto mamário.

Percebemos, ainda, que os HAC e os trabalhadores que neles atuam necessitam estar mais voltados para prevenir possíveis causas do desmame precoce, como o ingurgitamento mamário e as fissuras. Então, constatamos que se houver a manutenção do apoio a mulher, pelo HAC e seus profissionais, para o enfrentamento das dificuldades no AM, sua influência poderá ser decisiva na conservação do AM.

\section{Referências}

1. Lamounier JA. Experiência iniciativa Hospital Amigo da Criança. Revista da Associação Médica Brasileira, Belo Horizonte (MG) 1998 out/dez; 44(4):319-24. Acessado em: 20 jan 2003.

2. Rego JD. Aleitamento Materno: um guia para pais e familiares. São Paulo: Atheneu; 2002.
3. Lamounier JA. Promoção e incentivo ao aleitamento materno: Iniciativa Hospital Amigo da Criança. Jornal de Pediatria, Rio de Janeiro 1996 mar/abr; 72(6): 363-68.

4. Shimitz ME. A Enfermagem em pediatria e puericultura. Rio de Janeiro: Atheneu; 1989.

5. Poli LMC. Processo de aleitamento materno na perspectiva do cuidado cultural de enfermagem. [dissertação de Mestrado em Enfermagem]. Curitiba (PR): Pós-Graduação em Enfermagem, Universidade Federal de Santa Catarina e Universidade Federal do Paraná; 2000. $193 \mathrm{f}$.

6. Rezende MA, Sigaud CHS, Veríssimo MDLOR, Chiesa AM, Bertolozzi MR. O processo de comunicação na promoção do aleitamento materno. Revista Lat-Am Enfermagem, Riberão Preto (SP) 2002 mar/ abril; 10(2):234-8.

7. Gil AC. Métodos e técnicas de pesquisa social. São Paulo: Atlas; 1995.

8. Ministério da Saúde (BR). Conselho Nacional de Saúde. Diretrizes e normas regulamentadoras da pesquisa envolvendo seres humanos: Resolução no 196/96. Brasília (DF); 1996. 12 f. Disponível em: URL: <http://www.ufrgs.br/hcpa/gppg/res19696.htm>. Acessado em: 11 mar 2003.

9. Silva IA. O significado de amamentar para a mulher. In: Merighi MPB, Praça NS. Abordagens teórico-metodológicas qualitativas: a vivência da mulher no período reprodutivo. Rio de Janeiro: Guanabara Koogan; 2003.120p.p.135-51.

10. Souza LMB da. "Promoção, proteção e apoio?" representações sociais em aleitamento materno [dissertação de Mestrado em Saúde Pública]. Rio de Janeiro: Instituto Fernandes Figueira, Fundação Oswaldo Cruz;1996.128f

11. Ministério da Saúde (BR). Portaria MS/GM n 1.016, de 26 de agosto de 1993. Estabelece Normas Básicas para o Alojamento Conjunto. Brasília (DF). Diário Oficial [da] República Federativa do Brasil. Brasília (DF) 1993 set;167:13066.

12. Leopardi MT. Cuidado: ação terapêutica essencial. Revista Texto\&Contexto Enfermagem, Florianópolis (SC) 1997 set/dez; 6(3): 57-67.

13. Armellini PA, Segre AMC. RN. $3^{a}$ ed. São Paulo: Sarvier; 1991.

14. Miura E. Neonatologia: princípios e prática. Porto Alegre (RS): Artes Médicas;1991.

15. Pizzato M G, Poian VRL. Enfermagem Neonatológica. $2^{a}$ edição. Porto Alegre (RS): Luzzato Editores Ltda; 1985.

16. Van Der Sand ICP. Bem-estar da criança sempre em primeiro lugar: o processo de alimentação do lactente sob a ótica de mulheres-mães de ljuí (RS) [dissertação de Mestrado em Enfermagem]. São Paulo: Escola de Enfermagem, Universidade de São Paulo;1999. $190 f$.

17. Soares MEM, Giugliani ERJ, Braun ML. Uso de chupeta e sua relação com o desmame precoce em população de crianças nascidas em Hospital Amigo da Criança. Jornal de Pediatria, Rio de Janeiro 2003 jul/ago;79(4):309-16.

18. Beauchamp TL, Walters L. Contemporary issues in bioethics. $4^{\mathrm{a} e d}$. Belmont (TN): Wadsworth; 1994.

19. Amorim C. Princípio da beneficência e da não-maleficência. In: Urban CA. Bioética clínica. Rio de Janeiro: Revinter; 2003.

20. Almeida MS. Sentimentos Femininos: o significado do desmame precoce para as mulheres. Revista Texto \& Contexto Enfermagem, Florianópolis (SC) 1997 jan/abr;6(1):260-75.

21. Rea MF, Venâncio SI, Batista LE, Santos RG, Greiner T. Possibilidades e limitações da amamentação entre mulheres trabalhadoras formais. Rev Saúde Pública, Rio de Janeiro 1997 abr/mai;31(2):149-5.

22. Pinheiro AKB. Desmame Precoce vivenciado por mães adolescentes [dissertação de Mestrado em Enfermagem]. Fortaleza (CE): Faculdade de Farmácia, Odontologia e Enfermagem, UFC;1998.

23. Ichisato SMT, Shimo AKK. Aleitamento materno e as crenças alimentares. Revista Lat-Am Enfermagem,Riberão Preto (SP) 2001 set-out;9(5):70-6.

Data de Recebimento: 20/03/2004

Data de Aprovação: 22/12/2004 